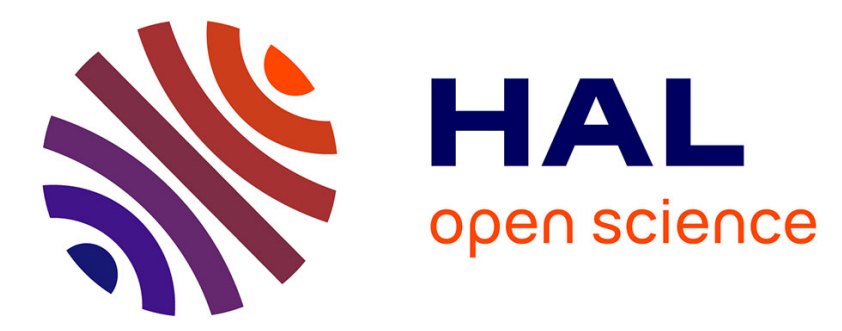

\title{
Intensive Innovation: A Semiotic View
}

Daniel Galarreta

\section{To cite this version:}

Daniel Galarreta. Intensive Innovation: A Semiotic View. 18th International Conference on Informatics and Semiotics in Organisations (ICISO), Jul 2018, Reading, United Kingdom. pp.63-72, 10.1007/978-3-319-94541-5_7 . hal-01920738

\section{HAL Id: hal-01920738 \\ https://hal.inria.fr/hal-01920738}

Submitted on 13 Nov 2018

HAL is a multi-disciplinary open access archive for the deposit and dissemination of scientific research documents, whether they are published or not. The documents may come from teaching and research institutions in France or abroad, or from public or private research centers.
L'archive ouverte pluridisciplinaire HAL, est destinée au dépôt et à la diffusion de documents scientifiques de niveau recherche, publiés ou non, émanant des établissements d'enseignement et de recherche français ou étrangers, des laboratoires publics ou privés. 


\title{
Intensive Innovation: A Semiotic View
}

\author{
Daniel Galarreta ${ }^{[0000-0003-4921-1442]}$ \\ Centre National d'Etudes Spatiales, 18, avenue Edouard Belin, 31401 Toulouse Cedex 9, \\ France \\ daniel.galarreta@cnes.fr
}

\begin{abstract}
We have entered a new innovation regime: that of acceleration and intensification. These situations of intensive innovation and disruption question the identity of the objects. The question of the identity of objects directly refers to epistemological questions. In particular, how objects happen in the world - do they exist before their descriptions? But the question of identity also refers to semiotic questions. In this paper, we will present a semiotic framework in order to analyse the question of how business or IT or Space systems emerge in an interdisciplinary environment. Namely we will present a multi-viewpoints semiotics. In parallel to this approach we will introduce an innovative design theory initiated by Armand Hatchuel and Benoît Weil: The C-K theory. We will then try to better understand what brings the two approaches closer together and what separates them.
\end{abstract}

Keywords: Intensive Innovation, Identity, Organisational Semiotics, Viewpoints, Multi-viewpoints Semiotics, C-K theory.

\section{Introduction}

According to Le Masson, Weil and Hatchuel [1] we have entered a new innovation regime: that of acceleration and intensification. Intensive innovation "means that all modes of value formation are nowadays concerned by a logic of innovation and technology is only one of those modes. One of the major evolutions today is the transition from a problem of optimizing enterprise capacity (involving decision theory) to a problem of expanding enterprise capacity (involving design theory).

Traditional, incremental innovation is no longer a sufficient guarantee to accompany the major changes that are disrupting our economy, especially as they occur more and more frequently.

Historically, efforts to rationalize design activity have given rise to theories that have enabled firms to adapt to a certain set design mode, in particular by organizing and structuring design offices. But these structures and associated theories today, however, struggle to account for situations of intensive innovation and disruption, where the identity of objects is constantly questioned [1].

The question of the identity of objects directly refers to epistemological questions, namely how it is possible to account for the existence of world objects on the one hand and their identity on the other. This amounts to questioning the way of thinking how 
objects happen in the world - do they exist before their descriptions? Are they constructions? - and is the identity of an object linked to its morphology, its functional characteristics, its use, its position in a technological phylum? But the question of identity also refers to semiotic questions, namely the way in which a language of any kind - that of advertising, of the industrial designer, as well as of the architect - tries to control the meaning and values of the objects it contributes to bring out in a cultural universe.

In this paper we will compare two answers to this question by placing ourselves within the framework of a reflection on innovation. We will first present a semiotic approach to the question designing multi-viewpoints systems (section 2) and then introduce an innovative design theory that builds its credibility on both the empirical results it achieves and the solidity of conceptual apparatus that it calls for to justify its methodology (section3). Once the two decors have been set, we go to a conclusion by showing how a semiotic interpretation can be given of the innovation process as modeled by the $\mathrm{C}-\mathrm{K}$ theory.

\section{$2 \quad$ A Semiotic Approach of Design}

In designing business or IT or Space system, a difficult task for the designers who cooperate is to find a common framework where they can efficiently share their knowledge on the same problem. Instead of considering the system they design from a single point of view (e.g. from a functional point of view or from an economical one) we could prefer to consider the system just as a signifying object compatible with all the viewpoints involved in the designing activity [2].

This requirement of interpretability justifies recourse to a particular disciplinary field: namely Semiotics. This requirement is not, of course, a substitute for the requirement of truth, reasonableness, plausibility, or any other kind of requirements that borrows its discourse from a logical theory. It is not a special case either. Thus formulas such as "the cat is on the carpet" or "a boat that can fly" are open to interpretation without being necessary to rule on their truth value. It is especially up to semiotic theories $^{1}$ to account for the conditions under which such formulas manifest their meaning.

According to $\mathrm{H}$ Gazendam, the approach that we are to present below is "a knowledge-oriented approach in organisational semiotics by the fact that knowledge is considered as representations or sign structures in the human mind, enabling adequate behaviour of the human actor" [4].

1 There are several semiotic theories. Broadly speaking, those oriented towards the study of signs and their dynamics, whose most important representative is CS Pierce, and those oriented towards the production and interpretation of speeches usually associated with F de Saussure. Greimas and Courtes define semiotics as a theory of signification. Its primary concern will therefore be to explain, in the form of a conceptual construction, the conditions for the grasping and production of meaning [3]. The Hjelmsevian semiotics to which we refer (see below) is clearly on Saussure's side. 


\subsection{A Multi-viewpoints Semiotics Methodology}

Rather than describing the outside world by trying to be as objective as possible, even if it means questioning the description we give of it ex post2, we will assume that all the descriptions we can produce are always made from particular viewpoints, and the objects that emerge from these descriptions do not pre-exist to these viewpoints and their interactions. This is the epistemological - constructivist - framework we adopt here 3.

In order to give a formal description of viewpoints, our approach refers - at least at start - to the language theory proposed by Danish linguist Louis Hjelmslev (18991965), Glossematics. Delving further into the question of Saussurian double distinction between form and substance and content (signified) and expression (significant), [5] proposes an in-depth analysis of the stratified character of the language on which we can build our definitions.

We then define the descriptive concepts, their relations and the operations that can be performed with them. This description constitutes the methodological level of a multi-viewpoints semiotics methodology.

This multi-viewpoints semiotics remains for the moment a methodology, since its epistemological level has not been yet established4.

\section{2 $\quad$ First Definitions}

We define a viewpoint as the correspondence on the content plane, that gives a form, namely a "linguistic value" to a substances:

- Viewpoint: substance $\rightarrow$ linguistic value;

- E.g. Viewpoint of Persian: sacred animal $\rightarrow \operatorname{dog}$ (opposed to cat, cow, and so on);

- E.g. Viewpoint of Hindus: pariah animal $\rightarrow$ dog (opposed to cat, cow, and so on).

We need to distinguish between a viewpoint and a view. This is analogous to the distinction between the function $f$ and a value $f(x)$ of this function for the element $x$.

- e.g. $\operatorname{dog}$ is a view for sacred animal in a Persian's viewpoint;

- e.g. dog is a view for pariah animal in a Hindu's viewpoint.

A view is - using the Hjelmslev's terminology - the manifestation of the form in the substance: the substance is the manifestant and the form is the manifestatum. Let us note the relation between substance and form can also be defined on the plane of expression. The opposition between a pronunciation (therefore phonemic substance) and a corresponding phonological notation (or a spelling that could be used as such -

2 Such an attitude will therefore correspond to a realistic scientific approach.

3 In other words, it is a matter of proposing a theory making it possible to construct semiotic objects.

4 The main reason is that the notion of "correlation" that is used is based upon the notion of negotiation, which is not yet defined using the notions of this semiotics itself.

5 For further details, see [5], [6] and [7]. The examples are due to Hjelmslev himself in [5] 
and therefore a form) is an example of such a relation. A viewpoint can therefore be defined also with respect to the plane of expression. Although this could seem odd, there is no problem with that since the two plane are according to Hjelmslev, equivalent,

We define the confrontation of two viewpoints by the semiotic function (or semiosis) between the two planes.
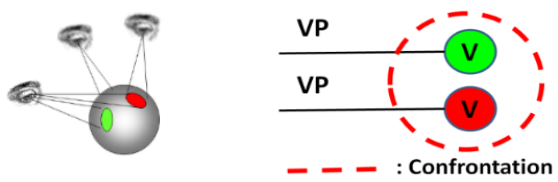

Fig. 1. Confrontation of viewpoints.

Two features of that semiotics need to be underlined. F1: A view cannot exist apart from a confrontation of viewpoints (justification is to be found in [5]); F2: A viewpoint can only be analyzed within a confrontation of viewpoints. (This results from the definition of a viewpoint and from F1).

What is empirically observed is the interaction of viewpoints corresponding to the different stakeholders of a project involved in the design of an object. Three cases need to be considered:

Confrontation of viewpoints (VPs): the views produced by each VPs make sense to the others, but are not compatible.

Correlation of viewpoints: After a negotiation process, all VP produce mutually acceptable views.

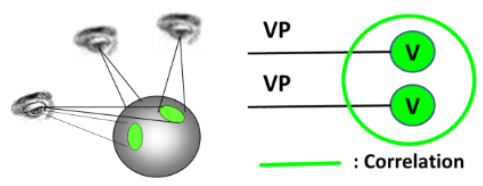

Fig. 2. Confrontation of viewpoints.

Two cases to be considered (empirically observed): (1) All of the considered VPs can evolve during interaction; (2) Only one VP is considered; the interactions with the other VPs are non-evolving processes. These VPs are put between brackets.
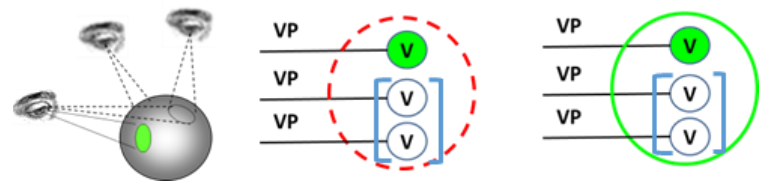

Fig. 3. Viewpoints put between brackets

The products of these three cases can be used as definitions of information, knowledge and data. Depending on whether there exists a correlation or a confrontation among all 
the viewpoints under consideration, we will have either Modelling Data or Schematization Data. The justifications of these definitions as well as the introduction of this semiotic approach can be found for instance in [7].

Table 1. Types of views according to viewpoints interactions.

\begin{tabular}{lll}
\hline & Confrontation of viewpoints & Correlation of viewpoints \\
\hline $\begin{array}{l}\text { All of the considered VPs } \\
\text { can evolve during interac- }\end{array}$ & Information & Knowledge \\
tion & & \\
$\begin{array}{l}\text { Only one Vp is considered. } \\
\text { These other VPs are put be- }\end{array}$ & Schematization Data & Modelling Data \\
tween brackets & & \\
\hline
\end{tabular}

Let us point out that scientific data correspond to Modelling Data, whereas Schematization Data correspond to the production of a code of expression (e.g. a conceptual graph) - and not of a content. (See [7])

The meaning of a view does not have the same practical value according to the context in which it is produced and more precisely according to the question to which it gives an answer. In the following we will try to propose a semiotic interpretation of what is a question. In order to do this, we will rely on a typology of ignorance, that is, on what we do not know proposed by Sylvain Bromberger, who defined three types of rational ignorance [8]:

Ignorance of type 1: 'I know questions whose correct answer I can't tell from incorrect ones: 'What is the distance between London and Paris?', 'How many arithmetic steps are absolutely required in a program for solving a set of linear equations? ', 'What is the Papago word for 'horse'?', 'What is the atomic weight of calcium?". Let us consider the first example. Only the viewpoint of topography which measures the distances between cities is a priori mobilized, independently of any other point of view. Answering a question of this type is tantamount to going from a schematization data with respect to the topographical viewpoint to a modeling data with respect to the same viewpoint.

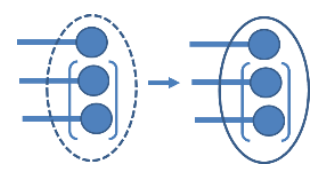

Fig. 4. Ignorance of type 1.

Ignorance of type 2: 'I know questions to which I know only incorrect answers: e.g. 'What are the heuristics by which a child discovers the grammar of his language?'. To know that the answers in the case of S. Bromberger's example are not good, it is necessary that I be able to grasp all the points of view necessary to produce an answer 
to the question ${ }^{6}$. Answering a question of this kind is tantamount to moving from a confrontation of points of view to a correlation of those same points of view.

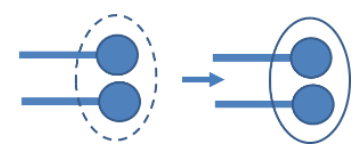

Fig. 5. Answer to an ignorance of type 2 .

Ignorance of type 3: We know problems that we can't solve: e.g. give some people the percentage of a solution of ethylene glycol in water and its density and they will figure out for you the vapor pressure of that solution at $20^{\circ} \mathrm{C}$. We accept here by hypothesis that there are viewpoints that we do not yet know and that must necessarily be mobilized and correlated both between them and possibly with viewpoints already present, in order to produce a satisfactory response. Answering a question of this type is equivalent to moving from confronting a collection of viewpoints to correlating a new collection of viewpoints, the latter being or not able to include all or part of the first collection.

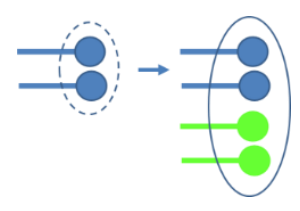

Fig. 6. Answer to an ignorance of type 3 .

Let's note that regardless of the type of ignorance, a question corresponds to a confrontation of viewpoints and an answer, to a correlation of theses viewpoints or of a superset of them.

Answering a question can be interpreted as an operation to produce or restore the identity of objects likely to be endowed with different levels of semiotic existences: virtual, actualized, or potential. The restoration of an object identity consisting in restoring or producing a realized semiotic level of existence [9].

It is obvious that it is the third type of ignorance that calls for interdisciplinarity, since it obliges us to mobilize exogenous points of view in relation to the usual multidisciplinary practices ${ }^{7}$. Similarly, breakthrough innovations will correspond to responses to this type of ignorance. It should nevertheless be noted here that innovation has the particularity of involving the creation of financial, economic value in the broadest sense, ethical and so on.

6 If that were not the case, I would have to admit that there are viewpoints that I still do not know and in the absence of which I cannot come up with a satisfactory answer. This situation would then correspond to the third type of ignorance

7 If one must be careful not to assimilate a viewpoint and a discipline, one can admit that the exercise of a scientific or technical discipline mobilizes viewpoints when it is analyzed at the semiotic level. 


\section{C-K Theory, a Theory of Innovative Design}

We will now introduce an innovative design theory initiated by Armand Hatchuel and Benoit Weil: The C-K theory. Why do we choose this theory? It is today one of the most cited theories of innovative design. It has had an impact far beyond the scope of innovation management [10].

But what further justifies our interest, however, is the way in which the methodology at work in this theory is interpreted in the semiotic framework we introduced ${ }^{8}$. The difference lies at the level of theoretical foundations or epistemological framework: mathematical in one case ${ }^{9}$, semiotic in the other. Besides, the $\mathrm{C}-\mathrm{K}$ theory shares with the semiotic approach presented the characteristic of questioning the identity of the objects it designs

We have not enough room in this paper to offer a comprehensive presentation of the $\mathrm{C}-\mathrm{K}$ theory. We will refer the reader to the above reference. We will mention the elements that are useful for our purpose.

\subsection{Assumptions and Definition of Design}

The four following points are quotation of [10]:

"1. We call K, a "knowledge space", the space of propositions that have a logical status for a designer $\mathrm{D}$. This space is always neglected in the literature, yet it is impossible to define design without such referring space.

2. We call "logical status of a proposition", an attribute that defines the degree of confidence that $\mathrm{D}$ assigns to a proposition. In standard logic, propositions are "true or false". In non-standard logic, propositions may be "true, false, or undecidable" or have a fuzzy value. A Designer D may use several logics. What matters in our approach is that we assume that all propositions of $\mathrm{K}$ have a logical status whatever it is, and we include here as a logical status all non-standard logical systems. In the following, we will assume for simplicity reasons that in $\mathrm{K}$ we have a classic "true or false" logic. But the theory holds independently of the logic retained.

3. We call "concept", a proposition, or a group of propositions that have no logical status in $\mathrm{K}$. This means that when a concept is formulated it is impossible to prove that it is a proposition of $\mathrm{K}$. In Design, a concept usually expresses a group of properties qualifying one or several entities. If there is no "concept" Design is reduced to past knowledge.

4. Definition 1 of Design: assuming a space of concepts $C$ and a space of knowledge $\mathrm{K}$, we define Design as the process by which a concept generates other concepts or is transformed into knowledge, i.e. propositions in K".

8 Since the C-K theory is interdisciplinary in its application, it remains a priori compatible with a multi-views points approach.

9 It is not possible to develop here this mathematical framework. See [11]. 


\subsection{The Dual Dynamics of Design}

Let us consider the following design task: design a "new tyres (for ordinary cars) without rubber". We use here an example borrowed from [11]. We define successively the initial concept and knowledge attached to this case.

Concept: "there exists a (non empty) class of tyres for ordinary cars without rubber" is a concept as it can be assumed as undecidable within our present knowledge.

Knowledge: Existing tyres for ordinary cars are all made with rubber and there are no existing, or immediately constructible, tyres without rubber. Moreover, no established and invariant truth forbids the existence of such new objects that we call "norubber tyres"

Therefore "no rubber tyres" form a class that corresponds to a formula that is undecidable in $\mathrm{K}$ and is indeed a concept.

Proving the indecidability of the existence of a class of object such as "no-rubber tyres", with respect to the available knowledge is called a disjunction operation from K to C.

[10] introduce then "expansions" in both $\mathrm{K}$ and $\mathrm{C}$ :

- "In K, we can attempt to "expand" the available knowledge (intuitively, it means learning and experimenting) if we want to reach a decidable definition of the initial concept

- In C we can attempt to add new properties to the first concept in order to reach decidability. This operation, which we call a partition is also an expansion of the definition of the designed object [...].

Assume that the concept of "non-rubber tyres" is partitioned by the type of material that replaces rubber. This depends of the knowledge we have in K about materials: for instance, plastics, metal alloys and ceramics. Thus we have three possible partitions: "non-rubber tyres with plastics", "non-rubber tyres with metal alloys" and "non-rubber tyres with ceramics". These partitions may create new objects. And testing these partitions may lead to new knowledge in $\mathrm{K}$, for instance new types of plastics, or new materials that are neither plastics, metal alloys or ceramics!"

"In C-K theory, it is crucial to distinguish between two types of partitions in space $\mathrm{C}$ : expanding and restricting ones":

- A partition is called an expanding partition if it attempts to expand the definition in our example of tyres by creating new tyres, which are different from existing ones

- A partition is called a restricting partition if it acts act as selectors among existing objects in K, for instance "tyres with white rubber".

"Expanding partitions have two important roles:

- They revise the definition of objects and potentially create new ones; they are a vehicle for intentional novelty and surprise in design;

- They guide the expansion of knowledge in new directions that cannot be deduced from existing Knowledge". 
"A design solution is the concept $\mathrm{Ck}$ is the first concept to become a true proposition in $\mathrm{K}$ ". Proving that corresponds to a conjunction operation from $\mathbf{C}$ to $\mathbf{K}$.

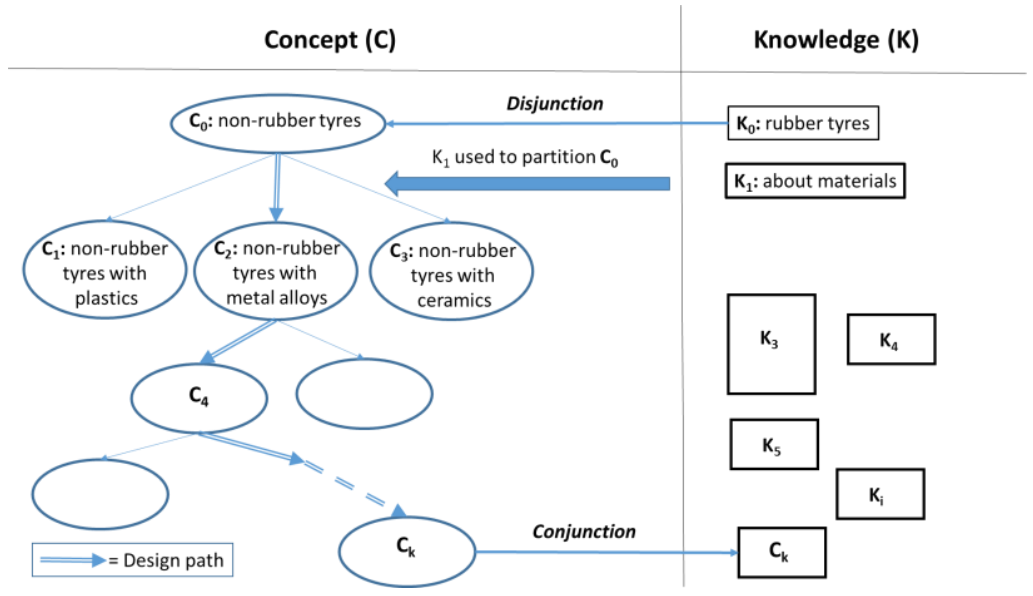

Fig. 7. C-K Diagram (from [11]).

\section{Conclusion: Toward a Semiotic Interpretation of the Innovation Process}

The semiotic framework we have presented, allows us to propose a semiotic interpretation of the innovation process as modeled by the $\mathrm{C}-\mathrm{K}$ theory.

A concept in $\mathrm{C}-\mathrm{K}$ theory will corresponds to a view that is produced during the confrontation of a collection of viewpoints. If we admit that a part of these viewpoints are put in parenthesis, this view corresponds to a schematization data.

The fact that in the example we mentioned, the class of "non rubber tyres for ordinary cars" can be seen as a special kind of set, called C-set, for which the existence of elements is $\mathrm{K}$-undecidable, is not an issue in semiotic approach: the signification of a view is independent of its semantic or logical acceptability.

Expanding partition $\mathrm{C}-\mathrm{K}$ theory generate new objects through chimeras and "crazy" concepts. From a semiotic point of view expanding partition summon (a) knowledge (views) that everyone can have about an object such a tyre and (b) a viewpoint that is usually correlated with other viewpoints that produce views about a tyre. In other words, according to our definitions, a "tyre without rubber", produce a modelling piece of data with respect to the viewpoint of materials.

According to $\mathrm{C}-\mathrm{K}$ theory an ontology of design such as the one proposed by this theory needs a dynamic frontier between invariant ontologies (viz. about the physical world) and designed ontologies. Since, according to us, the question pertains to semiotics, there is no formal boundary between an invariant ontology and a designed ontology. From a semiotic point of view, the differences between the two types of ontologies depends on the viewpoint that is adopted to analyzed the viewpoints that are correlated on one hand - among them physical viewpoints - and the viewpoints that enter in a 
confrontation on the other hand - and that required to be correlated in order to produce objects belonging to a designed ontology.

In $\mathrm{C}-\mathrm{K}$ theory voids in knowledge, should not be confused with the usual "lack of knowledge" about something that already exists or is well defined. This distinction corresponds from a semiotic point of view, to two types of ignorance that we have already considered. Two semiotic operations are therefore needed to produce a "piece" of knowledge in each case. As we saw above, the second case corresponds to the mobilization of new viewpoints - as well as already existing ones - in order to produce new semiotic objects and new pieces of knowledge.

These considerations of a sort should be in the future extended to further aspects of the $\mathrm{C}-\mathrm{K}$ theory.

\section{References}

1. Le Masson, P., Weil, B., Hatchuel, A.: Strategic Management of Innovation and Design, Cambridge University Press, (2010)

2. Galarreta, D.: Designing Space Systems in Multi-Viewpoints Semiotics. In: Liu K. (eds) Virtual, Distributed and Flexible Organisations. Springer, Dordrecht (2004)

3. Greimas, A. J., Courtés, J., Semiotics and Language: an Analytical Dictionary, Bloomington, IN: Indiana University Press (1983).

4. Gazendam, H. W. M., Organizational Semiotics: a state of the art report, Semiotix, Vol. 1, Issue 1. March 23, 2004. http://www.semioticon.com/semiotix.

5. Hjelmslev, L. : La stratification du langage. Essais Linguistiques. Editions de Minuit. Paris, pp. 45-77 (1971).

6. Galarreta, D.: A Semiotic Approach of contexts for Pervasive systems. 12th International Conference on Informatics and Semiotics in Organisations IFIP WG8.1 Working Conference University of Reading, UK. (2010).

7. Galarreta, D.: Are things, objects? A semiotic contribution to the Web of Things. Web of Things, People and Information Systems. 14th International Conference on Informatics and Semiotics in Organisations (ICISO 2013). IFIP WG8.1 Working Conference. Stockholm, Sweden (2013)

8. Bromberger, S.: On what we know we don't know. Explanation, Theory, Linguistics and How Questions Shape Them. University of Chicago Press and Center for the study of Language and information (1992).

9. Galarreta, D.: Approche sémiotique de la multidisciplinarité : contribution à l'analyse de l'interrogation d'un système à base de connaissances multidisciplinaires. Rochebrune (2014), http://www.gemass.fr/dphan/rochebrune14/index.html, last accessed 2018/04/18.

10. Hatchuel, A., Weil, B.: A New Approach of Innovative Design: an Introduction to C-K Theory, International Conference on Engineering Design ICED 03, Stockholm, (2003)

11. Hatchuel, A., Weil, B.: Design as Forcing: deepening the foundations of C-K theory, International Conference on Engineering Design ICED 07, Paris, (2007) 